\title{
ORTEGA ANTE LA CRISIS Y EL FUTURO DE LA ANTROPOLOGÍA
}

\author{
Ricardo SANMARTín ARCE ${ }^{1}$ \\ Universidad Complutense de Madrid
}

Resumen: Bajo la inspiración y las anticipaciones de Ortega se presentan en este ensayo ideas sobre el futuro de la Antropología Social y Cultural, abocada también al estudio de los cambios actuales en las sociedades modernas y las implicaciones metodológicas que comporta. Se presta una atención particular a la Antropología en Europa y a la obra reciente de antropólogos italianos con interesantes aportaciones que replantean el papel de los investigadores y de la etnografía misma.

Palabras clave: etnografía, crisis, sociedades contemporáneas.

Aвstract: Under the inspiration and anticipations Ortega it is possible to think about the future of Social and Cultural Anthropology, also dedicated to the study of current changes in modern societies and methodological implications involved. The article offers particular attention to anthropology in Europe and the recent work of Italian anthropologists interesting contributions to rethinking the role of researchers and ethnography lends itself.

KeYwORDs: ethnography, crisis, contemporary societies.

Decía Ortega que «eso que se llama 'crisis' no es sino el tránsito que el hombre hace de vivir prendido a unas cosas y apoyado en ellas a vivir prendido y apoyado en otras» ${ }^{2}$. "Hay crisis histórica cuando el cambio de mundo que se produce consiste en que al mundo o sistema de convicciones de la generación anterior sucede un estado vital en que el hombre se queda sin aquellas convicciones, por tanto, sin mundo. El hombre vuelve a no saber qué hacer, porque vuelve a de verdad no saber qué pensar sobre el mundo [...] el mundo en que vivía se ha venido abajo [...] Se mueve de acá para allá sin orden ni concierto; ensaya por un lado y por otro, pero sin pleno convencimiento; se finge a sí mis-

1 rsanmart@cps.ucm.es

2 Ortega y Gasset, J. 1994 (1947): En torno a Galileo. Madrid: Revista de Occidente en Alianza Editorial, p. 76. 
mo estar convencido de esto o de lo otro [... Por eso] en las épocas de crisis son muy frecuentes las posiciones falsas, fingidas» ${ }^{3}$.

Si Ortega escribiese hoy, tendría que reconocer que esto que llamamos crisis es, lamentablemente, el tema de nuestro tiempo. No me refiero solo a la crisis financiera que tanto paro sigue produciendo, sino a la crisis cultural que esa crisis económica expresa y, a la vez, alimenta. Se trata de una crisis ampliada por el marco de la globalización. Hemos conectado todo hasta percibir que la Tierra es un sistema con mariposas cuyo aleteo desencadena efectos inesperados. Hemos creado fenómenos cuya cifra ha traspasado barreras invisibles hasta ahora. Lo nuevo no es la ley que rige los fenómenos, sino la toma de conciencia, y a ello hemos llegado como efecto no buscado del crecimiento demográfico y energético. No ha cambiado la composición ni las cualidades del $\mathrm{CO}_{2}$, aunque sí la cantidad que producimos al consumir la energía necesaria para mantener el estilo de vida al que nos sentimos atraídos un número cada día mayor de seres humanos. Es cierto que ese mismo estilo de vida ha generado especialistas capaces de detectar el cambio climático y alertarnos a todos de sus posibles efectos, pero junto a sus avisos pesan más las imágenes que dan alas al consumo en dirección contraria. Ni las culturas difusoras ni las receptoras se libran del viento de las mariposas. Los dardos de la difusión han sido lanzados a la caza de bienes deseados, pero al recoger la presa nos hemos encontrado con efectos colaterales que han probado una vez más la desnudez del emperador. Solo ex post facto han sido capaces los especialistas de avisarnos de lo que ya había acontecido. No vieron llegar el empuje del Este derribando el Muro, ni la oscuridad suicida del nuevo siglo contra torres y trenes, ni las largas raíces desreguladoras e inmorales de la Crisis, ni el hambre de sensatez y dignidad del norte de África, de Oriente Medio o del creciente número de los indignados de tantas ciudades ${ }^{4}$. Simplemente queríamos vivir mejor. La novedad de tan humano deseo es su extensión. La gran conexión que ha eliminado la soledad en el espacio ha cambiado la cualidad del tiempo y la época. Hemos vuelto a Babel tras la dispersión que decretó nuestro castigo y, si en vez de levantar una torre hemos construido una red, el pecado, no obstante, ha sido el mismo: «excesiva unanimidad» 5 . Todos aspiramos al mismo modelo de bienestar, si bien, dentro del horizonte que a todos nos abarca, el fenómeno cobra nuevos significados. En realidad, esa común aspiración no implica una única cultura.

3 Ibíd. p. 89.

${ }^{4}$ En octubre del 2011 ya eran 951 ciudades de 82 países.

5 Sloterdijk, P. 2000: En el mismo barco. Madrid: Siruela. p. 17. 
Son muchos los observadores que, tras detectar la progresiva homogeneización de Occidente, insisten en el crecimiento paralelo del nacionalismo y el refuerzo del particularismo, de hecho ya lo veía Ortega en La rebelión de las masas. Se trata de fenómenos conocidos, de la tensión entre fuerzas centrípetas y centrífugas de una vida que se sostiene en pie, en equilibrio, por la velocidad con la que huye de sus raíces en la necesidad y por el hambre de un futuro que sacie y renueve su sed de significado y sentido. En el acelerado trayecto vital de nuestro mundo, el consumo de energía es la clave del equilibrio en medio de la velocidad, y es ahí donde la unanimidad resulta excesiva, tanto en el consumo de energía material como semántica. Ya no hay Dios que elija quién entra o no en el Arca, ahora estamos todos en el mismo barco, aunque si nos hemos bebido el mar, como reconocía el loco de La gaya ciencia ${ }^{6}$, y hemos borrado con una esponja el horizonte, nos encontramos varados en el desierto y sin rumbo a pesar de tener lleno el tanque de petróleo.

\section{Ortega, el futuro y la verdad}

Ortega presentó en repetidas ocasiones al hombre como un dramático gerundio entre el pasado, que posee como único patrimonio, y el futuro al que tiende buscándolo y en cuya tarea se realiza. Pero «ese pasado que somos no lo tenemos presente, no lo vemos sino en la medida y con la selección de él a que nuestro futuro nos invita, mejor dicho, nos fuerza [...] Lo que aún no es [...] consiste en pura urdimbre de amenazas, temores y esperanzas» ${ }^{7}$. Ya había confesado Unamuno que «el ahora es el esfuerzo por hacerse después, el presente el esfuerzo del pasado por hacerse porvenir, vivimos de recuerdos que al querer adelantársenos se nos hacen esperanzas [...] Tumba del ayer y cuna del mañana es cada instante nuestro espíritu... y el porvenir nuestro único reino de libertad...». Compartiendo el ser histórico del hombre, decía Ortega: «somos primero que nada temor y esperanza, que son dos emociones suscitadas por el porvenir [...y] el porvenir es lo que no está en nuestra mano, es lo problemático por excelencia»? El hombre de nuestro tiempo aparece como un náufrago perdido en la arena, porque cuando la crisis es tan amplia y honda como ahora, esto es, «cuando el

${ }^{6}$ Nietzsche, F. 1882: La gaya ciencia, n. ${ }^{o} 125$.

7 Ortega y Gasset, J. 1985: Europa y la idea de nación. Madrid: Revista de Occidente en Alianza Editorial, p. 133. El texto original es de 1951.

8 Unamuno, M. 2011 (1904): Mi confesión. Edición y estudio de Alicia Villar. Salamanca: Ed. Sígueme, pp- 20-21.

${ }^{9}$ Ibíd. p. 205. Texto original de 1954. 
problematismo [... del futuro] es extremo, como ahora acontece, el pasado no nos ofrece sugestiones aprovechables. Esto es lo que llamo - decía Ortega'haber perdido el pasado'. El hombre se encuentra hoy ante el mañana como desnudo de pretérito» ${ }^{10}$. «Esta grave disociación de pretérito y presente es el hecho general de nuestra época [...] de pronto nos hemos quedado solos [...] los muertos [...] ya no pueden ayudarnos [...] los modelos, las normas, las pautas, no nos sirven. Tenemos que resolvernos nuestros problemas sin colaboración activa del pasado» ${ }^{11}$.

Con todo, esa pérdida del pasado es fruto de la oscuridad del futuro, pues «donde el hombre propia y primariamente está [...] es siempre primero un vivir el porvenir ${ }^{12}$. Claro es que, en realidad, tener o no futuro es algo que solo acontece en el presente. Si interpretamos bien a Ortega lo que nos está diciendo no es tan distinto de lo que señala Bloch sobre la esperanza. Lo valioso del futuro es tenerlo ahora en el presente. Si Ortega nos presenta al hombre como un ser en gerundio, teniendo que realizarse, la fuerza para encarar su circunstancia la obtiene de ese milagro que consiste en tener futuro en el presente. «La ocupación con el porvenir es pre-ocupación. El porvenir nos ocupa porque nos preocupa [...y] a esto — preocuparnos - reaccionamos buscando medios para asegurar esa inseguridad. Entonces retrocedemos del porvenir y descubrimos el presente y el pasado como arsenales de medios [...] Al chocar, pues, con el porvenir [...] rebotamos en él y somos lanzados hacia lo que tenemos: presente y pasado» ${ }^{13}$. A ese patrimonio llegamos, pues, forzados a cumplir con la tarea de realizar el futuro al que la vida nos lanza, esa vida que tenemos como «verdad suprema, de la que las otras manan ${ }^{14}$ según Unamuno, y en la que nos sentimos empujados a «buscar la verdad, que es la vida» ${ }^{15}$. Pero, se pregunta Unamuno, “¿qué es la verdad? Esperemos que la vida nos responda, pues verdad es lo que da vida, y lo que da muerte no es verdad [...] Verdad se dijo primero por oposición a mentira y no a error: fue término de alcance moral $»^{16}$. Esa unión entre moralidad y saber, tan estrecha como bíblica, le llevará a Ortega a subrayar la precedencia del sistema de valores sobre el conocimiento de un modo muy similar a las palabras

${ }^{10}$ Ibíd. p. 206.

11 Ortega y Gasset, J. 1967 op. cit. p. 66.

12 Ortega y Gasset, J. 1983 (1958): Goethe - Dilthey. Madrid: Revista de Occidente en Alianza Editorial, p. 103.

13 Ibíd. p. 105. Ortega afirma que estas ideas las publicó ya en 1914.

14 Unamuno, op. cit. p. 31.

15 Ibíd. p. 52.

16 Ibíd. p. 58. 
de Unamuno: «El hombre no es solo ni principalmente conocedor, es creador; es más que inteligencia, es voluntad [...De hecho, los conocimientos] que poseemos y nos guían en la vida provienen de la necesidad de vivir y se han fijado por selección en la conciencia [...Esto es,] se conoce lo que hace falta conocer vitalmente $[. .$.$] El conocimiento es para vivir y no la vida para conocer» { }^{17}$. Ese orden vital que enlaza valor y conocimiento, esperanza, esfuerzo y porvenir, lo problemático y la libertad, lo da la verdad de la vida que exige hacerse, vivirse.

Esa exigencia de realización del sujeto en su circunstancia será, para Ortega, la exigencia de autenticidad, pues la única necesidad humana es la necesidad de verdad. También Heidegger veía "que el hombre se encuentra «arrojado» por el ser mismo a la verdad del ser, a fin de que, "ex-sistiendo" de ese modo, preserve la verdad del ser [...] De acuerdo con ese destino, lo que tiene que hacer el hombre en cuanto ex-sistente es guardar la verdad del ser. El hombre es el pastor del ser ${ }^{18}$, y experimenta su existencia como cuidado de esa verdad. Con su habitual rotundidad, afirmaba Ortega que «la vida sin verdad no es vivible [...] sin verdad no hay hombre. Este puede definirse como el ser que necesita absolutamente la verdad y al revés, la verdad es lo único que esencialmente necesita el hombre, su única necesidad incondicional. Todas las demás, incluso comer, son necesarias bajo la condición de que haya verdad, esto es, de que tenga sentido vivir» ${ }^{19}$. Y, según él, «el sentido de la vida no es, pues, otro que aceptar cada cual su inexorable circunstancia ${ }^{20}$ "tal y como ella es, precisamente en lo que tiene de limitación $»^{21}$, «y al aceptarla, convertirla en una creación nuestra [...] traducir la necesidad en libertad $\aleph^{22}$. Esto es, Ortega cuenta con que lo que caracteriza más específicamente toda circunstancia es lo que en ella sentimos que falta y nos limita: el hambre de verdad, los valores ausentes y las necesidades. De ahí que, finalmente, ese esfuerzo realizador, no solo en pos de la satisfacción de necesidades, sino también hacia el logro de los valores, le lleva a concluir que «el sentido y el valor de la vida $[. .$.$] se halla siempre en un mañana mejor» { }^{23}$, esto es, un mañana en el que, contando con la limitación de la necesidad, aceptándola y basándonos en ella, sepamos crear una mejor libertad. Con todo, es la falta

17 Ibíd. pp. 59-60.

18 Heidegger, M. 2013 (1949): Carta sobre el Humanismo. Madrid: Alianza, pp. 42-43.

19 Ortega y Gasset, J. 1981: El tema de nuestro tiempo. Madrid: Revista de Occidente en Alianza Editorial, p. 45.

${ }^{20}$ Ibíd. p. 51.

${ }^{21}$ Ibíd. 50.

${ }^{22}$ Ibíd. p. 51.

${ }^{23}$ Ibíd. p. 127. 
actual de claridad, la oscuridad del amanecer de un mundo nuevo, lo que impide divisar el horizonte y dificulta el escrutinio en nuestro arsenal de los medios adecuados para construir ese mañana. A su manera también Sloterdijk alude a esa misma dificultad. Tras la muerte de Dios, no vemos en nuestro pasado cuál es el acontecimiento inaugural que imprime «dirección al periodo actual» ${ }^{24}$.

En la inevitable mirada del presente hacia el pasado — por causa del futuroson varios los fenómenos que contribuyen a las dificultades apuntadas. Por una parte, el cambio en la cantidad de todas las cosas cambia la cualidad del caso y, por otra, la complejidad así creada oculta la concatenación causal y extrema el problema, de modo que los límites de la circunstancia que Ortega quería que viésemos para poder aceptarla y apoyar en ello una creación libre y esperanzada, se nublan en medio de la complejidad. La gran conexión en un único sistema mundial por la globalización representa el cambio cuantitativo que produce un salto en la cualidad de lo real.

También lo percibía Ortega cuando constataba que el mundo había crecido y la vida «se ha mundializado efectivamente [...] El contenido de la vida en el hombre de tipo medio es hoy todo el planeta [...y] esta proximidad de lo lejano, esta presencia de lo ausente, ha aumentado en proporción fabulosa el horizonte de cada vida ${ }^{25}$. La circunstancia ya no es de cada cual solamente. ¿¿Acaso es realista describir la circunstancia estadounidense sin los millones de inmigrantes hispanohablantes? ¿Podemos entender el mundo actual sin integrar en él el Islam? ¿y el Islam sin internet?. ¿Comprendemos hoy el capitalismo sin la China comunista? ¿Cabe entender la cultura de las libertades sin la música que nos difundieron los esclavos negros, sin la plasticidad de sus máscaras y colores, sin las sustancias medicinales extraídas lejos de Occidente? Y, siendo la circunstancia tan global como parece, al intentar leer los signos del porvenir en su horizonte y rebotar al pasado, no hallamos, sin embargo, un pasado tan unitario como el futuro al que ese supuesto arsenal común tendría que responder. No solo hemos perdido el pasado, como decía Ortega, sino que el pasado que encontramos carece de la solidaridad que el futuro nos reclama. La exigencia de creatividad crece por ello exponencialmente. En el patrimonio que Ortega nos lega al señalarnos el pasado y el presente, no podemos olvidar la necesidad, el hueco de la unidad que nos falta y en el que nacen el valor de la solidaridad y la imaginación creadora.

${ }^{24}$ SloterdijK, P. 2011: Sin salvación. Tras las huellas de Heidegger. Madrid: Akal, p. 182.

25 Ortega y Gasset, J. 1967 (1931): La rebelión de las masas. Barcelona: Círculo de Lectores, p. 67. 
La globalización ha hecho común la circunstancia y nos ha enrolado a todos en el mismo barco. Las mariposas han emprendido el vuelo y el barco zozobra en medio de la tormenta.

Si Heidegger está en lo cierto, «los tiempos de la historia se distinguen cualitativamente» ${ }^{26}$ y esa cualidad que los define "no significa otra cosa que la condensación — cristalización — de una objetivación de la vida dada en la historia ${ }^{27}$. El problema es que esa condensación que cualifica nuestra época está alimentada por las imágenes del deseo a cuyo logro se orienta el barco sin ver la orilla de un destino desconocido. Ortega pensaba que «lo que va a ser mañana la sólida realidad fue primero anticipación del deseo; de un deseo, entiéndase bien, que no está en nuestro arbitrio tener o no tener. Actúa, por lo visto, en la historia una fantasía necesaria que imagina el porvenir del hombre, lo dibuja como proyecto de ser, como vital programa. La realidad no es sino la ejecución, más o menos torpe, de ese argumento ${ }^{28}$. Según Bloch, en la medida en que esa fantasía se carga de valor, «el objeto ideal, actúa [...] como si [...] poseyera un querer propio que se dirige como un deber-ser a los hombres» ${ }^{29}$. Es más, la fantasía que imaginamos nos resulta inevitable porque posee la naturaleza de los mitos en los que creemos y, verdaderamente, no están la creencia en el consumo y en el modelo del mecanismo que embargan nuestra cultura ante la clara conciencia como lo están las ideas sobre sus efectos, pues con mitos y creencias leemos cuanto suponemos que entrevemos en el horizonte. De lo contrario habríamos vislumbrado con más acierto o habríamos cedido con más generosidad la voluntad para evitar crisis y explosiones sociales.

Muchos de los daños del pasado siglo, en opinión del premiado economista Stern, se percibían antes más claramente. «Esto de ahora es mucho más profundo porque causa daños mayores y tiene el inconveniente de que es a escala global. Además, no se ve como entonces se veía ${ }^{30}$. En el primer tercio del siglo XX se creía vivir «en un tiempo que se siente fabulosamente capaz para realizar, pero no se sabe qué realizar. Domina todas las cosas, pero no es dueño de sí mismo. Se siente perdido en su propia abundancia [...] de puro parecernos todo posible,

26 Heidegger, M. 2009: Tiempo e historia. Madrid: Trotta, p. 35.

27 Ibíd. p. 36.

28 Ortega y Gasset, J. 1981: El tema de nuestro tiempo. Madrid: Revista de Occidente en Alianza Editorial, p. 48.

29 Bloch, E. 2004: El principio esperanza I. Madrid: Trotta, p. 205.

30 Ruiz Mantilla, J. 2011: Entrevista a Nicholas Stern. El País Semanal, n. ${ }^{o} 1810,5$ de junio de 2011, p. 35. 
presentimos [...] la decadencia» ${ }^{31}$. Y de ella Ortega decía que «las decadencias, como los nacimientos, se envuelven históricamente en la tiniebla y el silencio» ${ }^{32}$. Esa ocultación del propio rostro es, quizá, una de las más problemáticas cualidades del problema que tipifica nuestro tiempo. Inmersos en él como en la niebla, no vemos su forma ni apreciamos su tamaño. Embotados por el ruido de la épo$\mathrm{ca}$, no identificamos la pregunta que nos formula el problema cuando este nos circunscribe. Vivimos un tiempo carente de drama, sin bien ni mal — por eso nadie parece capaz de dar un diagnóstico - un mundo feliz en la abundancia, a pesar de su crisis. Entre los efectos sentidos por la población y las lejanas mariposas hay una espesa red circunstancial tejida con titulaciones de deuda y deseos de mayor autonomía, de apalancamiento financiero y búsqueda de éxito, de ventas al descubierto o en corto que provocan desplomes bursátiles y ofertas de rescate o de impuestos a las rentas superiores, de valoraciones expertas e interesadas - que son meras opiniones ${ }^{33}$ - y un anhelo sostenido por modernas imágenes mitológicas que llenan la mente con un horizonte de posibilidades sin fin. Bajo las imágenes de los nuevos mitos hemos olvidado la única necesidad y tergiversado las otras que, además hemos satisfecho con una abundancia que nadie reclamaba. No sólo dañamos la verdad al producir bienes con su obsolescencia programada $^{34}$, sino también al fabricar artificialmente las necesidades mismas y forzar su percepción en el mercado. De un modo y otro, alteramos el sentido y jerarquía de los valores a la vez que degradamos las necesidades como simples pasos previos del placer de satisfacerlas. Al olvidar así la naturaleza de nuestra humanidad, hemos reducido el papel de las necesidades y vulnerado su función de límite formativo, su modo propio de operar como anclajes en la realidad, como conectores con el resto de la naturaleza, como fuerzas que nos sitúan en la red de la vida. Lejos de aquella pobreza cuya luz iluminó la infancia de Albert

31 Ortega y Gasset, J.1967 (1931): La rebelión de las masas. Barcelona: Círculo de Lectores, p. 73 .

32 Ortega y Gasset, J. 1981: El tema de nuestro tiempo. Madrid: Revista de Occidente en Alianza Editorial, p. 180.

33 Véanse las respuestas a los entrevistados en la premiada película documental Inside Job, 2011, de Charles Ferguson. El Nobel en Economía Paul Krugman calificaba en El País del 9 de septiembre de 2011, p. 16 de «descaro» el informe de la agencia de calificación Standard \& Poor's que, «junto con otras agencias [...] desempeñó un papel importante en la causa de esa crisis». La tardía reacción de los gobiernos instando la investigación sobre la falta de independencia de tales agencias, la tímida y solo provisional prohibición de las ventas al descubierto, o las reticencias ante la tasa Tobin, muestra las ataduras que merman la soberanía de los pueblos.

34 Véase http://www.rtve.es/noticias/20110104/productos-consumo-duran-cada-vezmenos/392498.shtml 
Camus ${ }^{35}$, y casi sin darnos cuenta, hemos permitido que haya ido cobrando peso en el imaginario cultural una visión de los límites como constrictores de un querer que no debiera tener fin ni impedimento.

\section{El imaginario y el hombre-masa}

Es más, el imaginario creado nos ha distanciado en exceso de la realidad y se interpone al contacto con ella acolchando su roce. Con todo, nuestros sofisticados sistemas de prevención no son inmunes a lo que Lévi-Strauss veía, pues los «medios ambientes [...] se integran en un sistema ideológico formado según leyes mentales [...y] los constreñimientos de la mente imponen [...] la coherencia $[\ldots]$ si es preciso que la representación de las relaciones del hombre con su medio ambiente sigan siendo consistentes. Lo que es preciso destacar aquí es que la consistencia se considera más importante que la relación con el mundo exterior. No es la imagen de la relación la que cambia sino la imagen del medio ambiente conservada en el mito. Dicho medio ambiente deviene imaginario, en lugar de ser reconocido como falso o inexistente, comparado con las circunstancias reales presentes» ${ }^{36}$. De ahí nuestra preferencia por la consistencia de un estilo de vida frente al daño climático, o que especulemos en Bolsa como si eso solo fuese una muestra de sagacidad económica, de dominio de los mecanismos del mercado, como si su incidencia solo dañase a quienes no son tan ágiles o inteligentes. Para ciertos consultores de inversiones en materias primas, la subida de precios de los alimentos básicos como consecuencia de la especulación en los mercados de futuros, no son más que «efectos colaterales no deseados del mercado» ${ }^{37}$. No parece sensato calificar esas conductas como económicas pues, en realidad, no son sino un juego imaginario con dramáticas consecuencias. Por eso, para salvar la tan alta y acolchada barrera que nos aparta de la aspereza de una realidad que se pretende detectar, el volumen de la queja ha de ser un clamor. Solo la voz de Chernóbil o de Fukushima, o las del 15-M en Madrid, New York, o en cualquiera de las 951 ciudades de 82 países a las que se ha extendido el movimiento, resultan audibles, aunque el silencio del hambre clame desde hace tiempo en el corazón de África.

35 Camus, A. 1958: El revés y el derecho. Discurso de Suecia. Madrid: Alianza Editorial.

36 LÉvi-Strauss, C. 1972. Estructuralismo y ecología. Barcelona: Cuadernos Anagrama, pp. 26-29-30-36.

37 Knaup, H., Schiessl, M. \& Seith, A. 2011. «El hambre cotiza en bolsa». El País Domingo, 4-IX-2011, p. 8. 
Nunca ha sido fácil identificar los problemas, sobre todo cuando los expertos elegidos por la propia sociedad para desvelarlos (contratados en el mercado o votados en la política) sobrevuelan con sus alas de mariposa el áspero suelo de la realidad, o se deslizan sobre moquetas rodeados de asesores y secretarios que filtran la información. Ya veía Ortega en el especialista «el prototipo del hombremasa ${ }^{38}$, «hermético y satisfecho dentro de su limitación» ${ }^{39}$, marcado por «esa condición de «no escuchar» [...] que [...] llega al colmo precisamente en estos hombres parcialmente cualificados. Ellos simbolizan [...] el imperio actual de las masas, y su barbarie es la causa más inmediata de la desmoralización europea ${ }^{40}$. Pero se trata de una forma peculiar de no escuchar. Ortega ya reconoció, mucho antes de la existencia de Internet, la cualidad de «gigantesco hecho» que tenían «los nuevos medios de comunicación [...que] han aproximado los pueblos y unificado la vida en el planeta ${ }^{41}$. Sin duda logramos una gran cantidad de información, pero — como ya se daba cuenta Ortega — «esa información tan copiosa se compone de datos externos, sin fina perspectiva, entre los cuales se escapa lo más auténticamente real de la realidad ${ }^{42}$. Para contrarrestar, pues, esa sorda y acolchada distancia entre lo real y su percepción, apunta Stern que «la macroeconomía hay que vivirla en el terreno» ${ }^{43}$, de lo contrario no se percibe el olor acre y dulzón de la pobreza, no se sienten la impotencia y la debilidad como barrotes de la cárcel que cierra la imaginación de los pobres, escasamente alimentada con monótonas experiencias.

\section{Antropología europea}

Ortega y Stern, con sus palabras, parecen invitarnos a investigar con el trabajo de campo etnográfico, la observación participante y la entrevista en profundidad, el tema de nuestro tiempo. Con todo, la Antropología del sur de Europa, tan influida por la universidad anglosajona, cuenta con un apoyo insuficiente para poder cubrir como sería necesario sus objetivos de campo. Ya Evans-Pritchard vio como un lastre la orientación tradicional ante el reto de la complejidad de la historia, y su predicción sobre el futuro de nuestra disciplina se

38 Ortega y Gasset, J.1967 (1931). La rebelión de las masas. Barcelona: Círculo de Lectores, p. 133.

${ }^{39}$ Ibíd. p. 136.

${ }^{40}$ Ibíd. pp. 136-137.

${ }^{41}$ Ibíd. p. 242.

42 Ibíd. p. 248.

43 Ruiz Mantilla, J., op. cit. pp. 35-36. 
ha cumplido en nuestro presente: nos hemos tenido que ocupar, efectivamente, del complejo estilo cultural de nuestras sociedades, de nuestro propio mundo urbano y moderno. Con todo, sus alumnos siguieron estudiando el honor, el parentesco, los campesinos, el compadrazgo, los pescadores, o los pastores del Mediterráneo mientras la proporción de sus estilos de vida en el conjunto de la población disminuía día a día, a medida que crecía su emigración a las ciudades y se transformaban en obreros de la construcción o de la industria, en servidores de la administración pública o empleados en el sector turístico. No deja de ser relevante, para entender la concepción de la disciplina, el hecho de que durante toda esa época tampoco se les ocurriese a los antropólogos extranjeros que nos visitaban estudiar la industria automovilística española o italiana, la cultura en el campo de nuestras empresas (salvo la notable excepción de D. Greenwood en Mondragón), las creencias de la sociedad secular, la vida cotidiana como característica — así lo veía Charles Taylor en 1989— de la modernidad occidental y del tipo humano que en ella se construye, esto es, de nosotros mismos. En todo caso, han sido los propios antropólogos europeos quienes han comenzado el estudio de la complejidad de su propia modernidad, algunos — como Carmelo Lisónestudiando su propia comunidad de origen. Sin duda, para que el desequilibrio entre ambas comunidades científicas se haya producido, deben haber influido, entre otras circunstancias, una distinta dotación presupuestaria, siempre mucho más potente en las universidades norteamericanas o inglesas frente a las italianas y españolas. Con todo, parece claro que, más allá de diferencias generales entre ambos mundos, esa historia ha marcado en exceso los objetivos de unos y otros. La escasez presupuestaria ha limitado las posibilidades de estudios a distancia comparables con los de las universidades anglosajonas, si bien, por otra parte, la atención prestada al propio mundo, queriendo mantener una mínima diversidad entre el observador y lo observado, ha terminado centrando su atención en la demología, el campesinado o las minorías étnicas durante demasiado tiempo.

Nuestras universidades han tardado en percibir la importancia del estudio de nuestras propias culturas con las técnicas de campo tradicionales empleadas en el estudio de otras culturas. Es más, en realidad, la vieja distinción nostros/ ellos, todavía en el siglo XX situaba la frontera de un modo poco crítico, más etnocéntrico que metodológico. Tanto en la universidad española como en la italiana, la modernización de la Antropología Social y Cultural se ha producido paralelamente al cambio en el foco de atención de sus investigadores. Sobre este problema escribió A. Sobrero Antropologia della città hace ya veinte años. En su libro se preguntaba sobre las dificultades que encara la Antropología al menos desde que en 1925 subrayase Park la conveniencia de estudiar el 
hombre civilizado más allá del estudio de las sociedades primitivas. De hecho, cuando Sobrero aborda la escritura de Hora de Bai, acercando Antropología y literatura para dar cuenta de su experiencia de campo en Cabo Verde, lo hace «assumendo come fonte della mia riflessione la stessa riflessione dei capoverdiani su Capo Verde» ${ }^{44}$. Sobrero, obviamente, va con éxito más allá de la reflexión nativa con la propia. La experiencia de campo consigue captar la antropología folk de los capoverdianos como material bruto, etnografía al fin y al cabo, sobre la que trabaja la propia reflexión antropológica del autor. Pero, si su texto experimental consigue buenos resultados en Cabo Verde, ¿por qué no hacer ese mismo experimento en Roma, Milán, Madrid o Barcelona? ¿por qué no hacerlo en Nueva York y Londres, París o Berlín? ¿Debemos esperar a que un antropólogo nativo de las Trobriand, un antropólogo Nuer o Azande aterricen en nuestras ciudades para convivir con nosotros, observarnos y entrevistarnos? ¿Acaso solo de ese modo podría hacerse una verdadera antropología de la modernidad contemporánea? De hecho, la Fundación Transcultura de París impulsó investigaciones de campo en Europa de antropólogos africanos y chinos, y no faltan tampoco casos de antropólogos japoneses y de Oriente Medio que desarrollaron su investigación de campo en España, por ejemplo, ya en los años ochenta del pasado siglo. Con todo, los resultados de esas investigaciones no dieron un vuelco ni al método ni a la teoría antropológica. Esto no significa que la calidad de dichas investigaciones no fuera positiva. Se trata de investigaciones y tesis doctorales que han obtenido la máxima calificación y que, por tanto, cumplen plenamente los criterios de calidad que se exigen en la comunidad científica. Lo que Sobrero nos hace ver es, pues, valioso, y su reflexión metodológica — como las de Piasere, Giacchè, Dei, Lupo, Simonicca, Minicuci, Palumbo, Papa y demás colegas italianos, presentadas en sus monografías y compilaciones sobre teoría, método y técnicas etnográficas, antropología de la religión, del teatro o del turismo - nos permite apreciar la verdadera dimensión del problema que todavía embarga de un modo excesivo a toda la antropología contemporánea, tanto en Italia como en España.

\section{Raíces de la aproximación cualitativa}

La alteridad y distancia entre sujeto y objeto de conocimiento no es algo que dependa solamente de una diferencia sustantiva entre la cultura del observador y

44 Sobrero, A. M., 1996. Hora de Bai. Antropologia e letteratura delle Isole di Capo Verde. Lecce: Argo, p. 9. 
la de los observados. Si la disciplina toma como objeto de estudio toda diferencia cultural, está tomando bajo su atención algo de naturaleza relacional. La alteridad es siempre recíproca y no cabe, por tanto, ignorar la presencia de nuestra cultura en la génesis misma del problema objeto de estudio. Según Dilthey - tan valorado por Ortega - la proximidad natural entre sujeto y objeto es lo que tipificaba las ciencias del espíritu. De ahí que Lévi-Strauss, recordando el precedente de la Física, señalase en 1950, en su introducción a la obra de Marcel Mauss, que «en una ciencia en que el observador es de la misma naturaleza que su objeto, éste es también parte integrante de su observación ${ }^{45}$. Dilthey, fiel a la observación del espíritu humano, proponía contemplarlo no como mera razón sino como un proceso vital cuya realidad integra querer, sentir y representar. Por eso, las preguntas que nos formula la vida al observarla «no pueden ser contestadas suponiendo un rígido a priori de nuestra facultad cognoscitiva; sólo se contestan mediante una consideración evolutiva —entwicklungsgeschichte- que parte de la totalidad de nuestro ser $»^{46}$. Es pues a la totalidad del ser personal a quien Dilthey encarga la tarea de responder en el campo de las ciencias del espíritu.

Según él, «por las venas del sujeto cognoscente construido por Locke, Hume y Kant no circula sangre verdadera sino la delgada savia de la razón como mera actividad intelectual [... mientras que] el hombre entero [... es] este ser que quiere, siente y representa como fundamento también de la explicación del conocimiento y de sus conceptos» ${ }^{47}$.

Para Dilthey, por tanto, son las cualidades mismas de lo humano, tal como se encuentran al contemplar la vida, las que, en consecuencia, pedirán al observador una configuración del método centrado en la comprensión (Verstehen) y, dado que "toda ciencia es ciencia de la experiencia» ${ }^{48}$, tendremos que comprender la experiencia de la vida de los hombres que observamos a partir de nuestra experiencia de la observación desarrollada al convivir con ellos. Con esa intención se lleva a cabo el trabajo de campo que ha tipificado la Antropología Social. Con la etnografía reunida y la comparación se pretende ir de la parte que su vida es, en relación con la vida de los hombres, y de la parte que es nuestra vida, al todo de la vida humana.

45 Mauss, M. 1971. Sociología y Antropología. Madrid: Tecnos, p. 25.

46 Ortega y Gasset, J. 1983 (1958). Goethe - Dilthey. Madrid: Revista de Occidente en Alianza Editorial, p. 169.

47 Dilthey, W. 1944 (1883). Introducción a las Ciencias del Espíritu. México: F. C. E. p. 6.

48 Ibíd. p. 5. 
Se trata, pues, de principios, advertencias y cautelas metodológicas en pro de la objetividad del conocimiento, que la moderna Antropología Italiana comparte con los viejos maestros y que tanto importan en ciencias naturales como en las ciencias sociales. Obviamente, no son, en nuestro caso, los valores materiales del observador, como en el caso de Heisenberg, los que interfieren en lo que se observa, sino los valores culturales. Pero si ello no ha impedido el progreso de las ciencias naturales ¿por qué ha de impedirlo en las sociales? Ya, al menos desde Vico y, desde luego con Dilthey, se apostó con claridad en favor de un enfoque científico humanista que cabe también apreciar en la obra de Max Weber a través de su propuesta del uso instrumental de los valores en la «relación de valor» ${ }^{49}$ como un recurso metodológico.

Para Vico «no obran correctamente [...] aquellos que transfieren a la práctica de la prudencia el método judicativo del que se sirve la ciencia: pues $[\ldots]$ al no haber cultivado el sentido común, ni haber seguido nunca lo verosímil, [...] no toman en consideración qué opinan de [la verdad] comúnmente los hombres, y si también a ellos esas cosas les parecen verdaderas ${ }^{50}$.

A ese respeto por lo que hoy llamamos la alteridad de la etnografía une Vico una intuición cuyo alcance no estaba entonces en condiciones de evaluar. Vico vislumbra como fuente de datos relevantes para su arte de la prudencia aquello que la propia sociedad no ha contemplado todavía, según los cánones y principios comunes de su cultura, como expresión de su propio espíritu y se arriesga a señalar la conveniencia de «investigar en las acciones humanas la verdad tal cual es, incluso partiendo de la imprudencia, la ignorancia, el placer, la necesidad o la fortuna ${ }^{51}$. El sentido común, lo que opina la gente, su ignorancia e imprudencia incluso, la conducta guiada por el placer o la necesidad, castigada por el azar de la fortuna, allí donde los propios autores de la historia no suelen mirar cuando lo que buscan es formalizar su propia imagen de lo humano, no sólo ha de ser igualmente investigado empíricamente para encontrar la verdad tal cual es, sino que puede ser incluso un valioso punto de partida, precisamente porque, al escapar formalmente de todo aquello que la sociedad reconoce y dice de sí misma y su época, constituye una singular vía para acceder a sus creencias efectivas, a la

49 Véase Weber, M. 1997 (1922). Ensayos sobre metodología sociológica. Buenos Aires: Amorrortu. S. A.

${ }^{50} \mathrm{VICO}, \mathrm{G}$. 2002. Obras. Oraciones inaugurales \& La antiquísima sabiduría de los italianos. Barcelona: Anthropos, p. 94.

${ }^{51}$ Ibíd. p. 100. 
parte oculta del imaginario que mantiene a flote la masa visible de su cultura, con cuya fuerza se empuja a ciegas la historia.

La Antropología ha dedicado más tiempo a las otras sociedades que a la propia o, en esta, a aquellos actores cuyo estilo de vida no es el nuestro o no tipifica ese gran ambiente cultural en el que, antes incluso de toda investigación, estamos ya sumergidos a través de la inevitable pertenencia que nos ha asignado la historia. Toda la observación participante que ha caracterizado el quehacer etnográfico como seña de identidad de nuestra disciplina, parece presuponer esa distancia o diferencia cuya existencia permite que el observador se sumerja en su objeto. Sobre ello reflexiona explícitamente L. Piasere en su L'etnografo imperfetto. En su texto encara el problema de la investigación repasando las distintas figuras metafóricas con las que la comunidad científica ha intentado hacer entender la peculiaridad del acercamiento cualitativo, la singularidad de un conjunto de técnicas tan sutiles y próximas a los hechos de la vida observada que le hacen afirmar que "gli etnografi conoscono come conosce la gente comune, con un aumento di attenzione $»^{52}$. Se trata de una afirmación bastante compartida en Europa, como cabe confirmar al recordar las ideas de Bernard Traimond sobre «la prise en compte du discours naturel» en su "Introduction à l'ethnopragmatique» ${ }^{53} \mathrm{o}$ el largo y experto ejemplo de Carmelo Lisón Tolosana cuya trayectoria de investigación resume en su Antropología Integral. Ensayos teóricos (2010) y que amplía en Teoría etnográfica de Galicia (2012). Coincido en todo ello con los colegas españoles, franceses e italianos citados ${ }^{54}$.

Para expresar ese punto de vista, una de las metáforas más usadas es la acuática de la inmersión, con su énfasis en el carácter envolvente que posee una experiencia tan plena. Con dicha metáfora también se subrayan los peligros y riesgos que corre una reflexión que necesita aire o distancia para poder pensar en medio de sus esfuerzos por salir a flote con un pedazo sólido de conocimiento. En ese medio cultural tan continuo y analógico de la convivencia, pudiera parecer que, si ya estamos por nacimiento sumergidos en nuestro propio universo cultural no cabría sumergirnos de nuevo como una exigencia metodológica, pues una supuesta re-inmersión solo garantizaría un ahogo epistemológico con toda

52 Piasere, L. 2002. L'etnografo imperfetto. Esperienza e cognizione in antropologia. Roma-Bari: Editori Laterza., p. 143.

53 Traimond, B. 2004. La mise à jour. Introduction à l'ethnopragmatique. Presses Universitaires de Bordeaux.

54 Sanmartín Arce, R. 2003. Observar, escuchar, comparar, escribir. La práctica de la investigación cualitativa. Barcelona: Ariel. 
seguridad. De ahí, pues, que todo antropólogo se lance siempre al agua con el salvavidas de una cierta alteridad cultural sustantiva a modo de defensa.

En realidad, cuando nos sumergimos en situaciones sociales de contextos a los que pertenecemos y cuya cultura compartimos, sigue siendo posible hacerlo como simples actores o como investigadores, si bien en este caso lo hacemos con otro tipo de salvavidas, no ya sustantivo, sino crítico. Más que la diversidad cultural, son la intención, la teoría y el método quienes convierten al actor en investigador. El problema está en el enorme esfuerzo que exige el logro de tan peculiar «aumento di attenzione», pues no se trata tan solo de un incremento en la intensidad, el problema no es únicamente la cantidad de atención necesaria, sino desde dónde se proyecta nuestra atención o desde dónde se percibe como investigador aquello que también llega a la persona en tanto que actor. Cuando Lupo destaca el papel de los jóvenes nahuas como etnógrafos interesados en recoger y poner por escrito los cuentos de los viejos en México, percibe con claridad el papel intermedio que desempeñan. Que los viejos cuenten aquello a sus jóvenes

«es como si 'el otro', a quien va dirigido el testimonio, estuviera ante todo dentro de la propia comunidad, y no fuera. Y, por otra parte, no es posible dejar de advertir la fractura existente entre la perspectiva cultural de los ancianos, por lo general iletrados (en el papel de 'informantes') y la de los jóvenes aculturados que los interpelan (en el papel de 'etnógrafos nativos') ${ }^{55}$.

Esto es, los jóvenes capaces de jugar ese papel novedoso en su contexto han sido aculturados previamente y, con todo, no suplantan el papel del propio Lupo como antropólogo, pues, de hecho, están creando con esa acción un hecho etnográfico adicional que Lupo observa y analiza. Esa aculturación de los jóvenes es un hecho cultural en la cultura que Lupo observa y usa a modo, no ya de salvavidas para su propia inmersión, sino — por seguir con el mismo juego de metáforas - como si de un submarino nativo se tratase, como si Lévi-Strauss se sirviera del estómago del rey de las focas para sumergirse con menor riesgo en la Gesta de Asdiwal y, con su ayuda, comprender mejor el sentido del mito americano. Se trata, sin duda, de una sofisticada estrategia de campo que rinde frutos inteligentes. Cabe, por tanto, multiplicar la división de la distancia entre sujeto y objeto cuando el espacio entre culturas se acorta y lograr así la creación

55 Lupo, A. 1998. «Los cuentos de los abuelos. Un ejemplo de constitución de la memoria entre los nahuas de la Sierra Norte de Puebla, México». Anales de la Fundación Joaquín Costa, N.o 15 . Huesca.p. 271. 
de un nuevo punto de vista crítico. Negar esa posibilidad, cuando los hechos prueban lo contrario, nos recuerda la paradoja del estadio infinitamente dividido e imposible de recorrer de Zenón de Elea. La experiencia de campo de nuestros colegas en distintos contextos etnográficos occidentales, europeos incluso, confirma la posibilidad de dicho recorrido o inmersión sin naufragar necesariamente.

Cierto es que, cuanto más próximo resulta el estilo cultural observado, más difícil parece el logro de esa atención intensificada. De una posición entre los observados y el observador marcada por el lastre tradicional entre lo simple y lo complejo, que tanto pesó en la Antropología desde sus orígenes, pasamos ahora a nuevas situaciones de campo caracterizadas no solo por la igualdad o incluso la identidad cultural entre ambos lados, sino incluso a muchas situaciones en las que la desigualdad se invierte y la posición del etnógrafo resulta en varios sentidos cualificada por cierta inferioridad en relación con el mundo que ha de observar. En los nuevos contextos urbanos, si el antropólogo no se limita a observar campesinos emigrados, minorías étnicas, etc. sino que se propone como meta comprender el mundo de la empresa, del arte, de la política, la sanidad o la cirugía, de la alta sociedad, o cualquier otro ámbito en el que con igual fuerza irrumpe nuestra cultura, pero del que normalmente quedan alejados los funcionarios de nuestras universidades, percibirá con claridad esa diferencia de un modo completamente distinto al que percibió en los contextos de campo tradicionales. Desde que el Profesor J. García Castaño se doctorase en 1989 con un estudio de campo sobre su propio Departamento bajo el título: «Transmisión cultural en una institución educativa universitaria. Análisis antropológico de las relaciones docente-discente», o con el reciente estudio de J. A. Fernández de Rota ${ }^{56}$ en el seno de los departamentos universitarios norteamericanos, la igualdad entre observador y observados ha ido ganando nuevo espacio. Probablemente esa igualdad facilita un acceso a la persona de los informantes no exenta de tensión. Con todo, como reconoce Piasere,

«nella società dell'etnografo occidentale questo accesso è altamente controllato sotto tutti i punti di vista: gli specialisti sono accessibili solo su appuntamento e spesso dopo mesi di attesa; gli amici stessi sono spesso accessibili su appuntamento telefonico e in tempi concordati; gli sconociuti sono accessibili o su appuntamento o tramite rituali spaziali rigidi, ${ }^{57}$.

56 Véase Fernández de Rota y Monter, J. A. 2012. Una etnografía de los antropólogos en EE. UU. Consecuencias de los debates posmodernos. Madrid: Akal.

57 Piasere, L. op. cit. p. 144-145. 
Pero el problema no reside solamente en el tiempo adicional que ralentiza la investigación, los trámites y ritualización del acceso, sino en la desigualdad que puede llegar a impermeabilizar a los informantes que necesitamos contactar. Si bien esa misma dificultad u opacidad para la observación es, sin duda, un primer dato relevante, pues nos informa de como nuestra cultura defiende la intimidad de la gestación de las decisiones y del hogar del poder, no por ello podemos conformarnos con datos tan opacos si queremos que el trabajo de campo rinda sus frutos en contextos occidentales de la modernidad.

Todo grupo humano ha marcado siempre sus fronteras de una manera simbólica y ha establecido controles y dificultades de acceso. Las normas locales son siempre una puerta de entrada controlada desde el interior de los grupos humanos, pero en la medida en que es mayor el poder que ese grupo controla, el acceso es siempre más difícil. Los antropólogos no podemos penetrar en ese mundo a bordo de una patera. Por otra parte, además del menor poder del etnógrafo ante especialistas cuyo saber no domina el antropólogo, o cuyo nivel social clasifica al propio del observador como de menor rango, debemos contar, como principal dificultad, la de hallar el lugar epistemológico adecuado para poder desplegar la observación. Sin duda, las situaciones de campo y las dificultades halladas son muchas y muy variadas. De hecho Piasere recorre la amplia serie de posibilidades, pues «l'interazione è un continuum di situazioni che vanno dalla negoziazione più spinta al piacere più intenso, dalla contrattazione più cosciente all'empatia più incosciente» ${ }^{5}$, a las que ańade aquellas otras formas emic categorizadas por los propios actores según la cultura de su contexto: la keneh o risonanza de los balineses, como "quel sentire-pensare che permette di cogliere non i «discorsi», ma ciò che la gente realmente dice» ${ }^{59}$, aquellos "aspetti di essere nel mondo e di agire nel mondo, attraverso i quali solamente i concetti nascono vivi» ${ }^{60}$, así como distintas formas de entender y practicar la empatía ${ }^{61}$.

Sin duda la inmersión, la empatía, la risonanza, la negociación, el diálogo, la observación consciente y la impregnación inconsciente, y mil maneras más de aprovechar la convivencia con los actores como fuente de etnografía nos nutrirán de datos que habrá que someter a un nuevo esfuerzo hermenéutico. Todo ello

58 Ibíd. p. 146.

59 Ibíd. p. 148.

60 Wikan, 1992. "Beyond the words: the power of resonance», American Ethnologist, 19, 3, p. 471.

${ }^{61}$ Véase Stein, E. 2004. Sobre el problema de la empatía. Madrid: Trotta. 
se tensa y resulta más difícil en los nuevos contextos urbanos y complejos de nuestra más actual modernidad. Son estrategias clásicas de la Antropología que ayudan a penetrar el universo cultural que deseamos comprender. Pero cuando ese universo es el nuestro, este mismo en el que estamos sin saberlo porque en él ganamos el sustento y el espíritu que nos mantiene vivos intentando hacer Antropología ¿cómo logramos esa inmersión de segundo grado, esa re-inmersión intensamente consciente, que nos permita encarar el objeto que hemos estado rehuyendo a lo largo de la historia de nuestra disciplina?

Nos resistimos al ensayo como si el intento mismo de cazar a ese que nos mira cuando nos asomamos al espejo fuese un suicidio epistemológico que no lograse desnudarnos. La solución hasta ahora adoptada ha sido usar las fracturas sociales internas generacionales, profesionales, de clase y sus diferencias culturales reconocibles de lengua local, del modo de vida, del estrato social, del género incluso para, ubicándonos en la perspectiva de uno de los lados de cada una de ellas, observar el otro, esto es, ubicándonos siempre en un lugar distinto del de nuestros observados como salvavidas de la alteridad. Pero quizá al final pudiera tener algo de razón Zenón de Elea, ya que observando el objeto desde esas fracturas y divisiones internas no terminamos de recorrer el estadio cultural y ni llegamos a la meta deseada. Ese temor epistemológico a encarar el problema se funda, a mi entender, en un miedo más hondo y vital, pues nos vemos forzados en el empeño a escrutar y desvelar los fundamentos de nuestro propio pensamiento, las imágenes que asumimos al creer en la realidad de la escena de nuestra historia, en cuyo ambiente desempeñamos como actores el papel de antropólogos. Por otra parte, no sabemos como acceder a los nichos del poder que efectivamente pesan en la toma de decisiones que marcan nuestro más vivo presente. Seguimos viéndolos como un objeto imposible para las modestas herramientas de nuestra artesanía etnográfica. Quizá en ambos temores resida el verdadero problema que embarga nuestro presente disciplinar.

Asumir ciertas imágenes y no acceder al contexto en el que se decide la historia no son fenómenos inconexos. La dicotomía nosotros/ ellos siempre ha resumido una historia de poder. Con la globalización, la alteridad se ha vuelto interna, pero sigue siendo un resultado del poder, de la fractura interna que provoca el poder que nos afecta. Quizá esas sean las dos manos con las que nos rodea nuestra más próxima circunstancia: la del poder social y la de la propia imaginación cultural. Nuestro mundo nos abraza desde atrás y nos tapa los ojos con ambas manos mientras nos reta preguntándonos "¿quién soy?». Y no tenemos ni idea de cómo responderle. Eso es lo que debiera constituir nuestro más agudo y difícil tema 
de observación. Ese cambio temático en el objeto de nuestras antropologías nacionales, o en el conjunto de la comunidad científica, produciría un verdadero salto en la modernización de la Antropología. Sin duda, es difícil desarrollar un programa de investigación orientado directamente al corazón de nuestras instituciones más altas y características. Su mera enumeración puede resultar chocantemente utópica como campo para el modesto trabajo etnográfico de los antropólogos: el interior de las corporaciones empresariales y financieras, la vida interna de «los mercados», el G20, los Think Tanks europeos y norteamericanos, las instituciones internacionales como el Parlamento Europeo, el Banco Mundial, el Fondo Monetario Internacional, la FAO, o las instituciones públicas y grandes empresas industriales de cada país, los centros de diseño y, sobre todo, esa densa niebla cultural difusa y penetrante que constituye, con sus abundantes y sutiles imágenes, el paisaje de fondo que nos envuelve y abruma en nuestra vida diaria. Si lo hacemos, reorientaremos la investigación etnográfica hacia el amplio campo de nuestras desconocidas representaciones colectivas, hasta nuestras más hondas creencias seculares, y así podremos encarar críticamente cuanto hallemos en el espejo de nuestra sensualidad y consumo, o en las canciones con las que abrimos el oscuro fondo de nuestras emociones, o en el arte escrito, compuesto o filmado a tientas por quienes abren su sensibilidad a los signos de este tiempo.

No será fácil acceder al interior de esas situaciones en las que los actores toman las decisiones clave y desarrollar allí nuestra observación participante. Para sumergirnos en tan altas piscinas habrá que adquirir la entrada que permita el acceso a club tan selecto. Caro y difícil, pero no menos lo ha sido en ciencias físico-naturales perseguir el Bosón de Higgs, la energía oscura, las supercuerdas o, en biología, el genoma humano y, no obstante, nuestras sociedades financian esos esfuerzos que lentamente abren el acceso a los secretos de la naturaleza. Si nuestras sociedades aceptasen financiar un número mucho mayor de trabajos de campo, si nuestras sociedades se convencieran de la distinta calidad de los datos cualitativos obtenidos con paciencia en el interior de nuestras instituciones clave y los etnógrafos pudieran seguir el hilo real de la toma de decisiones, si estuvieran presentes en los despachos y se reuniesen, como propone la investigación-acción participativa, con los actores al elaborar esas decisiones podrían comprender los factores culturales, categoriales, creenciales y morales que pesan como imágenes implícitas y configuran el marco del sentido de las cosas. O si fuésemos capaces de convencer a un número creciente de actores en esos contextos políticos y económicos de la necesidad de salir del propio mundo profesional para verlo desde el que profesan otras ciencias sociales como la Antropología y transformasen su unilateralidad disciplinar en interdisciplinar, quizá entonces, al hacer más porosas 
las fronteras profesionales entre actores, haciendo de los economistas no meros ejecutivos, sino observadores críticos de su propio mundo, y educando a los antropólogos en economía, en derecho, en ciencia y práctica política, en gestión de grupos y recursos; si hiciésemos real la convivencia que siempre ha tipificado la observación participante en los nuevos contextos en los que es real la vida occidental, moderna, compleja, o como decidamos nombrarla, quizá entonces entenderíamos mejor nuestra cultura.

Para ello tendremos que rescatar un lugar crítico desde el cual observar tras el acceso y que nos permita destapar los ojos librándolos del velo categorial que, en realidad, constituye el tema objeto de esa nueva observación que proponemos. Siempre ha parecido imposible tirar con nuestras manos de nuestro propio peso para saltar más allá y librarnos de nuestra propia sombra. Solo Peter Pan había perdido su sombra y podía volar. Era un personaje de ficción, no un antropólogo responsable. No es que el observador busque una pirueta epistemológica similar, esto es, librarse de la mediación de la propia cultura para poder estudiar esa misma cultura. Pero no desesperemos. No solo es imposible eliminar la propia cultura, sino que además no es necesario. Max Weber y Caro Baroja nos sugieren otra posibilidad. En realidad, es toda la tradición crítica alemana quien lo sugiere, y cuyo rastro podemos seguir hasta los filósofos de la sospecha y, de nuevo, hasta Vico o, como decía Caro, hasta los maestros griegos y romanos que supieron dibujar las claves de la figura antropológica. Todos ellos se dieron cuenta de que, en realidad, no cabe una ciencia sobre la cultura y el hombre sin un compromiso con alguna imagen de lo que fuere el ser humano, aunque no se formule explícitamente, pues siempre queda como figuración antropológica en el fondo del observador. Toda ciencia se funda siempre en presupuestos. En el caso de nuestra disciplina esa figuración de lo humano es cambiante. Lo exige la propia historia como creadora de esa figuración en marcha, siempre inacabada. Lo que Weber llamó relación de valor, Caro lo ampliaba, más allá de una u otra idea de valor, al conjunto entero de la figuración antropológica, a aquella idea de Dilthey del ser humano como este ser que quiere, siente y representa. Quizá el logro de los clásicos haya que precisarlo en términos del horizonte de nuestra época, y no me refiero solo a los clásicos de la Antropología que tan seriamente han estudiado Fabio Dei o Alessandro Simonicca ${ }^{62}$. Las figuras de Héctor y Aquiles, de Electra, Sócrates y demás héroes encarnaron una imagen del hombre con la que cabía comparar los hechos de los hombres reales observados en el trabajo

62 Dei, F. 1998. La discesa agli inferi. James G. Frazer e la cultura del Novecento. Lecce: Argo. Simonicca, A. e Dei, F. (curatori) 1998. Simbolo e teoria nell'antropologia religiosa. Lecce: Argo. 
de campo. Aquella creación, que nació ya de la inferencia — de una inferencia poética, creadora - permitía una comparación crítica, un contraste que - de acuerdo con Gadamer- permitía destacar en lo observado cuanto resultaba así relevante, significativo. Los valores ideales tienen ahora otra figuración porque el cambio de la historia ha ubicado en otro lugar la exigencia y el reto al que tenemos que responder; sus portadores llevan hoy un ordenador bajo el brazo y hablan inglés. D. Quijote y Sancho viajan por internet o se comunican, como los nahuas que estudia Lupo, con móviles que llevan sus mensajes surrealistas hasta el cielo. Dante baja hoy al infierno de la crisis y no encuentra en nuestras ciudades palabras con las que construir su poema. Aunque aquellas figuras clásicas se encarnan en imágenes diferentes, matizadas por el cambio de época, aunque el viaje, el cielo y el infierno estén hoy en otra parte, el ejercicio crítico sigue siendo posible si, pertrechados con la imagen adecuada, nos adentramos como Ulises en los despachos y cruzamos la línea roja en la que se juega la vida de los hombres.

\section{Bibliografía}

Bloch, E. (2004). El principio esperanza I. Madrid: Trotta.

Camus, A. (1958). El revés y el derecho. Discurso de Suecia. Madrid: Alianza Editorial.

Caro Baroja, J. (1985). Los fundamentos del pensamiento antropológico moderno. Madrid: C. S. I. C.

Greenwood, D., González, José Luis. (1992). Industrial Democracy as Process: Participatory Action Research in the Fagor Cooperative Group of Mondragón, (co-authors Julio Cantón Alonso, Ino Galparsoro Markaide, Alex Goiricelaya Arruza, Isabel Legarreta Nuin, and Kepa Salaberría Amesti). Assen-Maastricht: Van Gorcum Publishers.

DeI, F. (1998). La discesa agli inferi. James G. Frazer e la cultura del Novecento. Lecce: Argo.

Dilthey, W. 1944 (1883). Introducción a las Ciencias del Espiritu. México: F. C. E.

Fernández de Rota y Monter, J. A. (Ed.) (1989). Lengua y cultura. Aproximación desde una semántica antropológica. A Coruña: Ediciós do Castro.

- (2012). Una etnografía de los antropólogos en EE. UU. Consecuencias de los debates posmodernos. Madrid: Akal.

GiACCHÈ, P. (2004). L'altra visione dell'altro. Una equazione tra antropologia e teatro.

Heidegger, M. (2009). Tiempo e historia. Madrid: Trotta.

- (2013) (1949). Carta sobre el Humanismo. Madrid: Alianza. 
Knaup, H., Schiessl, M. \& Sith, A. (2011). «El hambre cotiza en bolsa». El País Domingo, 4-IX-2011.

LÉVi-Strauss, C. (1972). Estructuralismo y ecología. Barcelona: Cuadernos Anagrama.

Lisón Tolosana, C. (2010). Antropología integral. Ensayos teóricos. Madrid: Editorial Universitaria Ramón Areces.

- (2012). Teoría etnográfica de Galicia, Madrid: Akal.

Lupo, A. (1998). «Los cuentos de los abuelos. Un ejemplo de constitución de la memoria entre los nahuas de la Sierra Norte de Puebla, México». Anales de la Fundación Joaquin Costa, N. ${ }^{\circ} 15$. Huesca.

Mauss, M. (1971). Sociología y Antropología. Madrid: Tecnos.

Nietzsche, F. (1882). La gaya ciencia, n. ${ }^{\circ} 125$.

Ortega y Gasset, J. (1967) (1931). La rebelión de las masas. Barcelona: Círculo de Lectores

- (1981). El tema de nuestro tiempo. Madrid: Revista de Occidente en Alianza Editorial.

- (1983) (1958). Goethe - Dilthey. Madrid: Revista de Occidente en Alianza Editorial.

- (1985). Europa y la idea de nación. Madrid: Revista de Occidente en Alianza Editorial.

- (1994) (1947). En torno a Galileo. Madrid: Revista de Occidente en Alianza Editorial.

Piasere, L. (2002). L'etnografo imperfetto. Esperienza e cognizione in antropologia. RomaBari: Editori Laterza.

Ruiz Mantilla, J. (2011). «Entrevista a Nicholas Stern». El País Semanal, n. 1810 , 5-VI-2011.

Sanmartín Arce, R. (2003). Observar, escuchar, comparar, escribir. La práctica de la investigación cualitativa. Barcelona: Ariel.

Simonicca, A. (2004). Turismo e società complesse. Saggi antropologici. Roma: Meltemi.

- (2006). Viaggi e comunità. Propettive antropologiche. Roma: Meltemi.

Simonicca, A. e DeI, F. (curatori) (1998). Simbolo e teoria nell'antropologia religiosa. Lecce: Argo.

Sloterdijk, P. (2000). En el mismo barco. Madrid: Siruela.

- (2011). Sin salvación. Tras las huellas de Heidegger. Madrid: Akal.

Sobrero, A. M. (1996). Hora de Bai. Antropologia e letteratura delle Isole di Capo Verde. Lecce: Argo.

- (1997). Antropologia della città. Roma: NIS.

Stein, E. (2004). Sobre el problema de la empatía. Madrid: Trotta. 
TAYLOR. C. (1989). Sources of the self. The Making of the Modern Identity. Cambridge: University Press.

Traimond, B. (2004). La mise à jour. Introduction à l'ethnopragmatique. Bordeaux: Presses Universitaires.

Unamuno, M. (2011) (1904). Mi confesión. Edición y estudio de Alicia Villar. Salamanca: Ed. Sígueme.

VIco, G. (1995). Ciencia nueva. Madrid: Tecnos.

- (2002). Obras. Oraciones inaugurales \& La antiquísima sabiduría de los italianos. Barcelona: Anthropos.

Weber, M. (1997) (1922). Ensayos sobre metodología sociológica. Buenos Aires: Amorrortu. S. A.

Wikan, U. (1992). «Beyond the words: the power of resonance», American Ethnologist, 19,3 , pp. 460-482.

Recibido 6/09/2012

Aceptado: 9/11/2012 